\title{
VLOGA IZOBRAŽEVANJA ODRASLIH V RAZVOJU LOKALNE IDENTITETE
}

\section{Razvoj lokalnih skupnosti v goriški pokrajini in $v$ Trstu z okolico}

Z pnosti je zelo pomembna vloga zavesti o lokalni identiteti. Pojem lokalne identitete je treba razumeti kot produkt oblikovanja lokalne zavesti posameznikov, ki temelji na objektivnih kriterijih, med katerimi lahko omenimo: skupno dediščino lokalne skupnosti, enotna pravila življenja, skupne običaje, kulturo, šolanje in zgodovino. Pojem lokalne skupnosti izpeljujem iz identifikacije $\mathrm{z}$ vrednotami, ki so plod objektivnih skupnih pogojev življenja v neki skupnosti. Ta identifikacija pa je tudi produkt vzgoje in izobraževanja, saj se dejansko dogaja kot sprejemanje skupnih vrednosti skupine pobudnikov v nekem kraju. Pogoj za stopnjo lokalne identitete je stopnja in širina lokalne zavesti, ki se razvija pri ljudeh v njihovi medsebojni povezanosti v lokalni skupnosti s podobnimi skupnimi cilji življenja in razvoja njihove skupnosti.

Poznavanje zgodovine kraja oziroma lokalne skupnosti omogoča ljudem, da gradijo svojo identiteto in oblikujejo svojo prihodnost, daje jim lahko občutek varnosti in jim omogoča postavitev ciljev in strategij v konkretnem lokalnem razvoju. Prav zaradi tega ima pri izobraževanju lokalne in regionalne skupnosti ljudi ter širjenju demokratičnih odnosov med njimi zelo pomembno vlogo tudi poznavanje in proučevanje zgodovine kraja ali regije. $\mathrm{V}$ takih okoliščinah zanimanje za zgodovino tudi izraziteje raste. Ljudje povprašujejo po zgodovini svojega kraja. $V$ ta namen bi bilo potrebno poskrbeti v lokalni ali regionalni skupnosti za institucije, ki bi lahko zadovoljile interese občanov.

\section{INTERESI ZA LOKALNI RAZVOI SKUPNOSTI}

$\mathrm{Na}$ Slovenskem danes nastajajo institucije, ki skrbijo za izobraževanje v lokalni skupnosti.
Pobudniki za njihovo ustanovitev so predvsem posamezniki, ki so v svojem kraju začutili potrebo prisluhniti ljudem, predvsem njihovim interesom in jim nuditi možnosti za pridobivanje novih znanj. Tako so nastali programi za izobraževanje odraslih, ki dajejo vse možnosti za temeljitejše poznavanje zgodovine kraja, lokalne ali regionalne skupnosti. Omenjeni programi pa pomenijo tudi iniciativo za nadaljnji razvoj študijskih krožkov.

Učenje zgodovine lokalne skupnosti ali regije pomeni odkrivanje podrobnosti zgodovine posameznega kraja, kar pa je nadaljnja pot za temeljitejše učenje in izobraževanje. To je še toliko bolj pomembno, saj ljudje v posameznih lokalnih skupnostih še danes ne poznajo preteklosti svoje ga kraja, kajti zgodovinopisje ni posegalo $\mathrm{v}$ podrobnosti opisa življenja in zgodovine posameznega kraja, temveč je interpretiralo le tiste življenjske situacije, ki so bile pomembne za državo. Zato je danes interes za raziskovanje in razvoj zgodovine posamezne lokalne skupnosti še posebej velik v manjših slovenskih krajih, saj so ljudje začeli iskati svojo preteklost v kraju, kjer živijo, in odkrili, da je lokalna skupnost, čeprav majhna, v zgodovini že imela veliko vlogo.

Njihova značilnost je, da je delo razširjeno in izobraževalno usmerjeno po vsej lokalni skupnosti ali regiji. $V$ ta namen poteka izobraževanje odraslih $\mathrm{v}$ različnih slovenskih krajih: $\mathrm{v}$ Ajdovščini, Velenju, Drežnici in Ilirski Bistrici. Tako se je pokazalo, da so bile na lokalni ravni podrobnosti o življenju majhnih skupnosti v prejšnjih časih veliko bolj pomembne, kot so danes.
Dr. Monika GovekarOkoliš Filozofska fakulteta $v$ Ljubliani 


\section{O RAZVOJU IN POMENU MAJHNIH LOKALNIH SIKUPNOSTI V SLOVENSKI ZGODOVINI}

Za primer smo izbrali Primorsko, ki je v svoji zgodovini imela zelo močno prosvetno izobraževalno vlogo, saj je izobraževanje odraslih potekalo v manjših lokalnih skupnostih. Razcvet tovrstnega delovanja je zaslediti $\mathrm{v}$ drugi polovici 19. stoletja in vse do prve svetovne vojne. Med oblike delovanja v lokalnih skupnostih pa lahko štejemo društva, ki so bila $\mathrm{v}$ zgodovini izobraževanja odraslih zelo pomembna. Sprva so se društva na Slovenskem sploh oblikovala v letu 1848 , ko so se prebivalci vseh narodov avstrijskega cesarstva organizirali v najrazličnejša društva. Nastala so prva društva med Slovenci, kamor se je vključevala predvsem slovenska inteligenca, kulturniki, duhovniki, študentje in dijaki. Ti so se v letu 1848 povezali v društva na Dunaju, v Gradcu in Ljubljani $\mathrm{z}$ imenom Slovenija (Prunk 1992). Glavna značilnost teh društev je bilo prizadevanje za razvoj slovenske politike (program Zedinjene Slovenije). Pomen teh društev pa je bil toliko večji, ker so s svojim

$\mathrm{Na}$ Primorskem so $\mathrm{V}$ 2. polovici 19. stoletja delovala številna društva. delovanjem in propagando vplivala na to, da se je zganila večina slovenskega kmečkega prebivalstva, vključno s kmečkim meščanstvom (Prunk 1992). To je spodbudilo nastanek in širjenje novih društev na slovenskem ozemlju znotraj Avstrije.

Kot primer lahko prikažemo goriško in tržaško regijo v drugi polovici 19 . stoletja. Znotraj avstrijske polovice habsburške monarhije sta pripadali isti upravni enoti: kot dežela Goriška in mesto Trst $\mathrm{z}$ okolico. Na teh območjih so v omenjenem času delovala številna društva, zlasti kulturnoprosvetna, ki so se širila tudi na podeželju. V številnih društvih (pevskih, bralnih, športnih in telovadnih, podpornih društvih, učiteljskih, političnih, gospodarskih, dijaških ...) je izobraževanje ljudi dobilo poseben pomen. $\mathrm{V}$ njih se je spodbujalo in razvijalo prosvetno delo, širila se je splošna razgledanost (pismenost, gospodarska znanja), nacionalna zavest in identiteta ter razvoj slovenske kulture. $\mathrm{Ob}$ tem pa se je razvijala tudi lokalna identiteta, ki se je kazala v skrbi ljudi za razvoj kraja, za medsebojno pomoč, za dvig splošne izobrazbene, kulturne, gospodarske ravni. $\mathrm{Na}$ omenjeni način so društva pre- našala znanja in stališča, ki jih ljudje v takratnem času ne bi dobili nikjer drugje. S tem so društva omogočala priložnostni razvoj vsakemu posamezniku, saj so se ljudje v njih prostovoljno srečevali v skladu s svojimi interesi, medsebojno so ustvarjali možnosti za uspešno individualno in kvalitetno ter spontano izobraževanje v lokalni skupnosti. S tem so si pridobili sposobnosti za nadaljnje samoizobraževanje, ki je bilo pomembno v času (med svetovno vojno in po njej), ko so društva zgubljala svojo vlogo. Na osnovi odprte komunikacije so se $\mathrm{v}$ društvih znotraj lokalne skupnosti ljudje izpopolnjevali $v$ znanju, prenašali so izkustva in informacije. Tako so bila slovenska društva eden od temeljev izobraževanja slovenskega prebivalstva v obdobju, ko smo bili Slovenci pod Avstrijo, kar se je pokazalo tudi na Goriškem in Trstu z okolico.

$\mathrm{V}$ drugi polovici 19. stoletja in do prve svetovne vojne se je oblikovalo zelo veliko društev. Med prvimi pa so bila bralna društva. Kot lahko ugotavljamo iz literature, so morali ljudje sami postaviti temelj ustanovam, ki so jim omogočile, da so se kulturno dvigovali. $\mathrm{S}$ tem pa so se razvijale manjše lokalne skupnosti, ki so odigrale pomembno vlogo $\mathrm{v}$ izobraževanju odraslih.

Začetki društev na Goriškem segajo v leto 1848, ko so goriški Slovenci junija ustanovili lastno Slavljansko bravno društvo. Kmalu po ustanovitvi je štelo 160 članov (Murovec in Humar 1957). Za cilj je imelo dvigniti poučevanje in samoizobraževanje slovenskih prebivalcev, vendar je delovalo le do leta 1850 . To je bilo eno prvih prosvetnih društev na Slovenskem. Naslednje leto je bilo ustanovljeno bralno društvo v Kanalu in leta 1851 v Bovcu (Murovec in Humar 1957).

Tudi v Trstu je bilo leta 1849 ustanovljeno Slavljansko društvo (Pahor 1970). To je bilo, kot omenja Pahor, sprva zaprto nižjim slojem prebivalstva, ki niso zmogli visoke članarine (18 oziroma 14 goldinarjev na leto), vendar je kljub temu vzpostavilo stike z okoliškim, pretežno kmečkim prebivalstvom. Stiki so bili trojni: 1 . V društvo so se včlanili bolj premožni in razgledani okoličani, vendar je bilo teh malo (leta 1865 le šest oseb). 2. Druga oblika stikov je nastala na osnovi posredništva okoliških učiteljev, ki so kot pevovodje ali cerkveni orglarji vodili svoje pevce na čitalniške prireditve (nastopi pevcev iz posameznega okraja). 
Tretjo obliko stikov pa so pomenili čitalniški izleti v okolico, povezani $\mathrm{z}$ nastopi (Pahor 1970). Stiki posameznih društev so širili v okolico umetne in posvetne pesmi ter narodnega duha, prav gotovo pa so utrjevali tudi lokalno identiteto. $S$ tem so bili povezani tudi začetki podeželskih čitalnic in nadaljnji razvoj podeželskega društvenega življenja.

Vendar je bilo delovanje prvih slovenskih društev tudi na Goriškem in v Trstu z okolico kmalu oteženo zaradi Bachovega absolutizma (1850-1860), ki je zatiral vsakršno politično in ljudskoprosvetno delovanje. Šele z zlomom absolutizma in uvedbo novega ustavnega življenja po letu 1860 je ljudskoprosvetno delovanje lahko ponovno izraziteje oživelo (Prunk 1992). Na Goriškem in v Trstu se je to pokazalo, podobno kot drugod po Slovenskem, v ustanavljanju čitalnic. To so bile institucije, ki so jih sprva ustanavljali po mestih in trgih, v katerih sta se združevali razvijajoče se slovensko meščanstvo in narodno zavedna inteligenca. $V$ čitalnicah so $\mathrm{z}$ govori utrjevali in širili narodno zavest, razpravljali so o političnih vprašanjih, gojili narodno petje, plese in igre (Govekar 1996). Prva čitalnica na Slovenskem z imenom Slovanska čitalnica je bila ustanovljena leta $1861 \mathrm{v}$ Trstu (istega leta so bile ustanovljene tudi v Ljubljani, Celju, Mariboru in kasneje še drugod) (Prunk 1992).

Že istega leta je začelo delovati tudi društvo $\mathrm{v}$ mestu Gorici z imenom Slovenska čitavnica Gorica. Cilj in namen društva je bil narodna omika (Gaberšček 1932). V prvih letih obstoja čitalnice so organizirali vrsto prireditev (veselice, pevske nastope, koncerte, tombole, govore, plese). Poleg Gorice sta dobili leta 1864 čitalnici tudi Ajdovščina in Vipava. Čitalnica v Ajdovščini je znana po tem, da je takoj ustanovila svojo knjižnico, knjige pa je pošiljala tudi po vaseh (ib.). Tako se je kmalu oblikovala zami-

Ustanavljanje podeželskih citalnic je priporočal Josip Godina-Vrdelski (18081884), ki je leta 1865 predlagal ustanovitev čitalnic v Škednju, pri Sv. Ivanu, v Rojanu, Barkovljah, na Proseku, Opčinah, v Bazovici in na Katinari (Pahor 1970). Ta priporocila niso bila brez uspeha. Časopis Slovenec je omenjal, da si je v Rojanu neki kmet zelo prizadeval, da bi se kar najhitreje ustanovila citalnica (Slovenec, 1865). sel, da bi tudi na podeželju ustanavljali čitalnice. $S$ tem so bile dane prve zamisli o širjenju ne le nacionalne identitete, temveč tudi lokalne, kar je omogočalo nadaljnji lokalni in regionalni razvoj skupnosti. Leta 1866 so se ustanavljale čitalnice po vaseh, v Podragi v zgornji Vipavski dolini in v Skopem na Krasu ter v Idriji. Tako so dobili čitalnico v Kanalu, Braniku in Idriji leta 1866 , leta 1867 v Solkanu in Komnu, leta 1871 pa je bila ustanovljena čitalnica $\mathrm{v}$ Kobaridu (Murovec in Humar 1957).

Najstarejša čitalnica
na Goriškem je bila,
ustanovljena v.
Tolminu leta 1862.

Za nas je bil še posebej pomemben zakon o društvih $z$ dne 15 . novembra 1867 , ki je pospešil nastajanje društev $\mathrm{v}$ šestdesetih in sedemdesetih letih 19. stoletja. Ta so se širila po posameznih vaseh in omogočala razvoj majhnih lokalnih skupnosti. Številna so bila slovenska društva, ki niso bila pod vplivi avstrijske politike. Poleg teh društev so se v sedemdesetih in osemdesetih letih 19. stoletja oblikovala tudi nemška (Schulverein) in italijanska društva (Pro patria, Lega Nazionale), katerih namen je bila germanizacija in iredentacija slovenskega prebivalstva (Pahor 1970a).

Analiza društev na Goriškem ter društev v Trstu in okolici kaže, da je imelo mesto Gorica do leta 1914 skupaj 88 društev, mesto Trst pa 94. V Goriški pokrajini je bilo 17 krajev s svojimi društvi. Od teh je bilo največ (11) društev v Podgori. V Trstu z okolico pa je bilo 44 krajev s svojimi društvi, od katerih jih je imel največ, kar 33, Sv. Ivan (Sancin-Reharjeva, 1970). Veliko število in pestrost društev glede na njihov namen delovanja kažeta, da je bilo lokalno kulturno-prosvetno delo zelo povezano $z$ društvenim delovanjem.

Lokalno prosvetno-izobraževalno delo je bilo sprva usmerjeno v širjenje nacionalne kulture, širjenje slovenskega jezika kot učnega jezika po šolah in drugih institucijah, skrbelo je za razvoj kraja, nastanek kulturnih institucij in ohranjanje starih. Boj za ohranjanje slovenskega jezika, kulturne dediščine in razvoja gospodarskih znanj znotraj društev je bil tako izrazit, da na Goriškem in v Trstu z okolico pred prvo svetovno vojno skorajda ni bilo domačije, ki ne bi imela naročenih nekaj slovenskih časopisov in knjig. Med časopisi so bili znani: Slovenski narod, Soča, Slovenski gospo- 


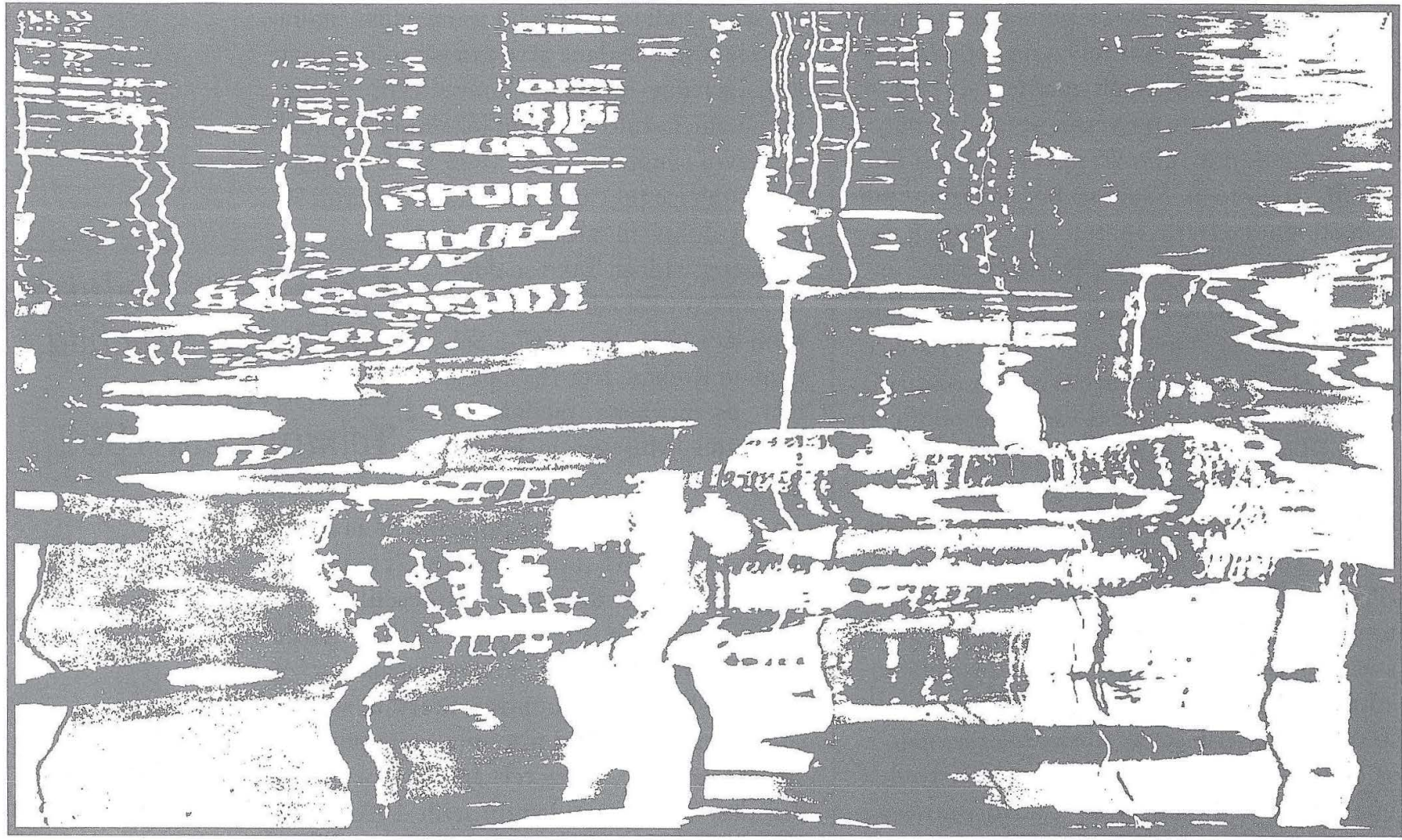

dar, Edinost, Naša sloga in Gospodarski poučnik. Prejemali so tudi Zvon, Slovana, Mir in knjige Slovenske matice, Družbe sv. Mohorja in knjige Društva sv. Jeronima. To nam kaže, da je bila pismenost med slovenskim prebivalstvom na Primorskem (Goriškem in Trstu) dovolj velika. Pomembno vlogo so za to imele ljudske knjižnice in bralna ter podporna društva, ki so nastajala po deželi. Na primer v Gorici je leta 1882 nastalo Bralno

Društva so odigrala pomembno vlogo $v$ boju za slovenski jezik. in podporno društvo. Nastajale so čitalnice (Kubed, Dekani, Vipava) in šolske ter učiteljske knjižnice. Učiteljske knjižnice, ki so jih ustanavljala posamezna učiteljska društva na Primorskem, so predvsem skrbe-

le, da je med učitelji krožila slovenska literatura, zlasti s pedagoško-didaktično vsebino (Iz Zaveze ..., 1891).

\section{PRVE POTUJOČE KNIIŽNICE}

Poleg tega so začele delovati tudi prve slovenske potujoče knjižnice. Za prvo je poskrbela Narodna Prosveta v Gorici že leta 1905. Leta 1906 sta nastali potujoči knjižnici v Mirnu pri Gorici in v Neblem ob italijanski meji. Obe je osnovalo društvo Adrija, ki je v naslednjem le- tu še širilo razvoj potujočih knjižnic (Kolerič 1970). Namen kulturno-prosvetnih društev je bil izobraževanje članov s pomočjo društvenih knjižnic in predavanj. Pred prvo svetovno vojno so zbirali knjige za osrednjo ljudsko knjižnico. Potrebni denar za nabavo knjig, vezavo, prenos, prevoz ter društvene omare so si pridobili z nastopi in prireditvami. Ljudje so se po posameznih krajih morali znajti na različne načine, da so lahko ohranili, kar so imeli, in razvijali naprej to, kar so si želeli, to je utrjevali so nacionalno in lokalno identiteto.

Prizadevanja ljudi za razvoj lokalne skupnosti so bila velika. Leta 1913 so ustanovili Muzejsko društvo v Gorici. Prizadevali so si za odprtje Narodnega muzeja. Muzejsko društvo je že v letu ustanovitve kupilo štiri redke slovenske knjige iz protestantske dobe: dve knjigi Primoža Trubarja, Ta celi Psalter Dauidov... iz leta 1566 in Ta celi Catechismus... iz leta 1584, in dve knjigi Jurija Dalmatina, Karszanske lepe molitve ... iz leta 1584 in Biblia... iz leta 1583 (Gaberšček 1934). Od prvih skromnih tiskov in redkih bralcev Slavljanskega bravnega društva v Gorici in Slavljanskega društva v Trstu je slovenska beseda postopoma našla pot $\mathrm{v}$ vsako najmanjše slovensko naselje in v vsako hišo na Goriškem in v Trstu (Kolerič 1970, str. 130). 


\section{ŠIIRJENJE LOKALNE ZAVESTI PREKO DRUŠTEV}

Med kulturno-prosvetna društva, ki so imela pomembno vlogo pri širjenju lokalne zavesti na Goriškem in Trstu, pa lahko poleg že omenjenih čitalnic, bralnih društev in ljudskih knjižnic uvrščamo tudi pevska, tamburaška, godbena, izobraževalna, športna in telovadna društva (Sokol, kolesarska, planinska društva, nogometni klubi) (Sancin-Reharjeva 1970).

Pomembna so bila tudi druga društva, ki so nastajala v drugi polovici 19. stoletja. Med njimi omenimo delavska in politična društva. Znano je bilo Delavsko bralno društvo v Idriji, ustanovljeno leta 1884. Društvo je imelo veliko prosvetno vlogo, saj je imelo svojo čitalnico, knjižnico in pevski zbor. Sprva ni bilo strankarsko opredeljeno, vendar se je to zgodilo na prehodu iz 19. v 20. stoletje (Murovec in Humar 1957). Politični razkol pa ni bil značilen le za omenjeno društvo, temveč tudi nasplošno za takratni čas. Slovenci so ustanavljali: 1. narodnonapredno, 2. katoliško stranko in 3. delavsko socialdemokratsko stranko. To je pomembno zato, ker je politična diferenciacija vplivala na cilje in delovanje posameznih društev, ki so imeli močan vpliv na oblikovanje lokalne identitete. To se je kazalo v tem, da so prosvetna društva dobivala jasnejše strankarsko-politične poteze, ki so se kazale po posameznih lokalnih skupnostih, boj za narodnostne pravice pa je stopil bolj v ozadje.

Med narodnonaprednimi društvi omenimo Narodno prosveto, ki je bila ustanovljena na pobudo narodnonaprednega tabora leta 1905 v Gorici. Njena naloga je bilo pospeševanje splošne izobrazbe, ustanavljanje čitalnic in knjižnic, prirejanje različnih predavanj, narodnih veselic, izdajanje brošur ter ustanovitev slovenskega gledališča v Gorici (Murovec in Humar 1957). Na pobudo narodnonapredne stranke je bila leta 1907 ustanovljena Zveza narodnih društev v Gorici, v katero je bilo leta 1909 vključeno 101 prosvetno društvo, leta 1910 pa kar 120 društev s 7000 člani (ib.).

Ustanavljala so se delavska društva, med katerimi omenimo Delavsko izobraževalno društvo v Gorici, ustanovljeno leta 1910. Značilnost tega društva so bila javna predavanja. Tudi v Trstu je bilo pred letom 1910 ustanovljeno podobno društvo. Nastajala so še druga delavsko-prosvetna društva, v Solkanu, Pevmi in v Mirnu (Murovec in Humar 1957).

Poleg teh so bila pomembna šolska (Družba sv. Cirila in Metoda) in učiteljska društva za posamezne šolske okraje. Pomembne organizirane oblike prosvetnega dela so potekale znotraj strokovnih organizacij, na primer $v$ pekovskem društvu, ribarskem društvu, Zvezi slovenskih delavk, Zvezi slovenskih trgovskih pomočnikov in trgovskem izobraževalnem društvu (Sancin-Reharjeva 1970). Delovala so tudi razna gospodarska društva: kmetijske in vrtnarske družbe, vinarska in sadjarska društva, posojilnice, hranilnice, zavarovalne zadruge, zadružne zveze in banke (ib.). Ustanavljala so se tudi podporna društva, na

Mladinsko društvo Adrija je sodelovalo z goriško Trgovsko-obrtno zadrugo in društvom Narodna Prosveta, s katerima so skupaj odprli javno knjižnico $v$ goriškem Trgovskem domu (ta je v prvem letu izposodila $4500 \mathrm{knjig}$ ) (ib.). Adrija je bila $\mathrm{v}$ letu 1904 pobudnik za uvedbo slovenskih napisov v slovenskem delu dežele (namesto nemško-slovenskih), prizadevala se je za ustanovitev pisarne za brezplačne pravne nasvete $v$ Gorici in za sistematično spremljanje razmer na jezikovni meji.

primer Delavsko podporno društvo, Dijaška kuhinja, Narodni sklad, razni zavodi in druga društva, med katerimi so bila lovska, strelska, Zveza županov in podžupanov posameznega okraja in posameznih slovenskih občin (Sancin-Reharjeva 1970).

Mladina je ustanavljala dijaška društva, ki so imela pomembno prosvetno vlogo $\mathrm{v}$ lokalni skupnosti. Med njimi omenimo Akademično ferijalno društvo Adrija, ustanovljeno leta 1902 v Gorici. Društvo je bilo pomembno, ker je vključevalo veliko študentov na Goriškem (Stergar 1978). Njihovo delovanje je bilo zlasti narodnoobrambno. Prirejali so ljudske shode, na katerih so se zavzemali za slovenske šole in ustanovitev slovenske univerze v Ljubljani. Omenjeno društvo je uresničilo zahtevo po ustanovitvi podporne dijaške kuhinje v Gorici leta 1907 (ib.). Mladi so si prizadevali za razvoj ljudskega knjižničarstva in do leta 1914 ustanovili na Goriškem sedem ljudskih knjižnic (Stergar 1978). Na ta način so mladi širili v majhne lokalne skupnosti svoje ideje in interese za razvoj nacionalne in lokalne zavesti.

Omeniti moramo tudi Slovensko Akademično ferijalno društvo Balkan, ustanovljeno
AS $3-4,0$ 
leta 1907 v Trstu. Tako kot za goriško Adrijo velja tudi za Balkan, da je s svojo organizacijo in delovanjem kmalu postal središče mladinske dejavnosti v Trstu. Uspeh njegovega delovanja je viden $\mathrm{v}$ številu ustanovljenih ljudskih knjižnic v letih 1907-1913 (Stergar 1978). Že od leta 1909 se je društvo zavzemalo za ustanovitev osrednje slovenske javne ljudske knjižnice v Trstu.

Večina društev na Goriškem in v Trstu je aktivno delovala do prve svetovne vojne. Med njo so prenehala delovati ali pa je bilo njihovo delovanje prikrito. Ljudje so si prizadevali za ohranjanje društvenega življenja, ki pa po vojni ni moglo obnoviti tako širokega delovanja. Kljub temu so si zgradili trdno lokalno identiteto in s tem dokazali, da so skrbeli za svoj lokalni razvoj, ki je hkrati pomenil tudi njihov nacionalni in osebni razvoj.

\section{SKLEP}

V zgodovini našega naroda lahko spoznamo, da je društveno življenje in delovanje dobilo poseben pomen prav zaradi izobraževanja ljudi. Slovenski človek je postal pismen, zavedal se je svoje nacionalne identitete, saj je bil pozoren na nacionalne, politične, kulturne in druge vsebine, ki so jih prinašali slovenski časopisi in knjige. Lahko so jih prebirali in si jih sposojali $\mathrm{v}$ čitalnicah in knjižnicah ali jih kupovali v slovenskih založbah (Mohorjeva). Prav prek društev, v katera so se vključevali prostovoljno in skladno s svojimi interesi, so bili deležni medsebojnega učenja, prenašali so razna znanja in izkušnje ter na osnovi tega oblikovali smotre dela društva, dokler je bilo mogoče. S tem so se posamezniki v društvih priložnostno razvijali, pridobivali poleg znanj tudi nekatere oblike samostojnega učenja. Med te prav gotovo sodi oblikovanje določenih osebnih lastnosti človeka, to je samostojnost, načrtnost, odločnost, motivacija za izobraževalno delo, kar je mogoče videti v zgodovini delovanja društev. Ljudje so na osnovi pobudnikov v kraju sami gradili in delali za svoj osebni razvoj in razvoj kraja. $\mathrm{Na}$ ta način se je oblikovala tudi zavest o lokalni identiteti, kar se je še posebej pokazalo z ustanavljanjem kulturno-prosvetnih, gospodarskih, podpornih in strokovnih društev. Ljudje so morali sami postaviti temelje ustanovam, ki so jim omogočale, da so se kulturno, gospodarsko razvijali, s tem pa so se razvijali tudi na lokalni ravni. To je danes za nas nov izziv, da sami oblikujemo sebe in podobo kraja, $v$ katerem živimo. Najprej je pomembno samoizobraževanje za spoznanje lastne identitete. Ta se kaže tudi z vključitvijo v lokalno skupnost, v kateri se danes s pomočjo vodij skupin (študijskih zgodovinskih krožkov) išče lokalna identiteta. Pri raziskovanju lokalne zgodovine prihajajo v ospredje njene podrobnosti. Ljudje raziskujejo različne vidike življenja, ki niso vključeni v zgodovinske knjige. Bolj do izraza prihajajo podrobnosti lokalnih kulturnih aktivnosti (kar nam kaže primer Goriške in Trsta), sploh pomembni dogodki v posameznih krajih glede zgodovine, antropologije, etnologije in lokalne ekonomije. Vidnejši so socialni momenti in prostovoljna združevanja posameznikov, ki se še posebej prizadevajo za razvoj lokalne aktivnosti izobraževanja odraslih, saj skrbijo poleg izobraževanja tudi za krajevne časopise, krajevne prireditve itd. Vse, kar kaže pot in raven življenja ljudi v posamezni lokalni skupnosti, vodi ljudi sprva $v$ raziskovanje zgodovine kraja, v katerem živijo, in v iskanje lokalne identitete, na osnovi katere lahko oblikujejo nadaljnje oblike dela in načrtujejo razvoj kraja.

\section{LITERATURA}

Gaberšček, A.: Goriški Slovenci, I. knjiga, samozaložba, Ljubljana, 1932.

Gaberšček, A.: Goriški Slovenci, II . knjiga, samozaložba, Ljubljana, 1934.

Govekar, M.: Vloga prosvetnih društev in gimnazije v Gorici pri prebujanju slovenske narodne zavesti $v$ letih 1848-1914; v: Andragoška spoznanja, št. 3, 1996.

Iz Zaveze slovenskih učiteljskih društev; Iz koprskega okraja; v: Popotnik, 25. april, Maribor, 1891.

Kolerič, T.: Nastanek, razvoj in uničenje slovenskih knjižnic; v: Prosvetni zbornik, Slovenska prosvetna zveza, Trst, 1970.

Murovec, I. in Humar, J.: Od čitalnic do Svobod; v: Goriški zbornik 1947-1957, Okrajni svet svobod in prosvetnih društev Gorica, Nova Gorica, 1957.

Pahor, D.: Pregled razvoja osnovnega šolstva na zahodnem robu slovenskega ozemlja; v: Osnovna šola na Slovenskem 1869-1969, Slovenski šolski muzej, Ljubljana, 1970a.

Pahor, S.: Prebujanje slovenske narodne zavesti; v: Prosvetni zbornik, Slovenska prosvetna zveza, Trst, 1970.

Prunk, J.: Slovenski narodni vzpon, DZS, Ljubljana, 1992.

Sancin-Rehar, L.: Slovenske organizacije; v: Prosvetni zbornik, Slovenska prosvetna zveza, Trst, 1970.

Slovenec, 26. 8. 1865, str. 259.

Stergar, J.: Oris zgodovine Počitniške zveze Slovenije, Izvršni odbor Počitniške zveze Slovenije, Ljubljana, 1978. 